\title{
Preparation and Electrochemical Characterization of Concrete Containing Microencapsulated Calcium Nitrate Corrosion Inhibitor
}

\author{
Changkyu Kim ${ }^{1}$, Reece Goldsberry ${ }^{1}$, Ahmad Ivan Karayan ${ }^{1}$, Jose Milla ${ }^{2}$, Marwa Hassan ${ }^{3}$, and Homero Castaneda ${ }^{1, *}$ \\ ${ }^{1}$ Department of Material Science and Engineering, Texas A\&M University, College Station, TX 77840 \\ ${ }^{2}$ Louisiana Department of Transportation and Development, Baton Rouge, LA 70802 \\ ${ }^{3}$ Department of Construction Management, Louisiana State University, Baton Rouge, LA
}

\begin{abstract}
We present the preparation and inhibition behavior of rebar in the presence of calcium nitrate (CN)-containing microcapsules with concentrations of $0.50,2.00$, and $5.00 \mathrm{wt} . \%$ in concrete. From both open circuit potential (OCP) and electrochemical impedance spectroscopy spectra, it was found that an addition of microcapsules containing $\mathrm{CN}$ corrosion inhibitor into concrete beams successfully repassivated or maintained the passivity of the rebar when the concrete was cracked. This corrosion inhibitor repassivated the rebar by forming a passive layer on the rebar surface under the crack. This repassivation process was evident by an increase of OCP values to more positive values or by stable OCP values at around $-100 \mathrm{mV}$ vs SCE. An increase in phase angle after corrosion activation for the sample with 2.00 wt.\% microcapsule clearly showed this repassivation process. The optimum concentration for maintaining the passivity on rebar in the cracked concrete was found to be $5.00 \mathrm{wt} . \%$.
\end{abstract}

\section{Introduction}

Corrosion of the reinforcing steel inside of concrete structures is one of the main causes of structure degradation and eventual failure of the concrete structure. The corrosion of the steel reinforcement can be due to multiple process such as: chloride ingress, $\mathrm{CO}_{2}$ ingress (carbonation), or other changes in the local area of the embedded steel [1]. The ingress of these aggressive agents will break down a protective passive that is formed on the steel reinforcing bar due to the high alkalinity of the concrete.

Chloride ingress is one of the major leading causes for corrosion of the rebar in reinforced concrete since chloride can penetrate through the concrete matrix [2]. Initially the rebar is in a passive state that protects the rebar from corrosion. This passive layer is due the high alkalinity of local environment, with $\mathrm{pH}$ values ranging from 12.5-14 depending on the properties of the concrete [3]. Corrosion due to chlorides occurs when the concentration of chlorides at the rebar surface rises to a critical threshold to break down the passive layer.

To extend the service life of reinforced concrete structure it has been shown that the addition of corrosion inhibitors into the concrete matrix will minimize corrosion. The most common ways corrosion inhibitors are added to reinforced concrete are: added to fresh concrete as an admixture, applied on the hardened concrete surface also known as migrating corrosion inhibitor and surface-applied corrosion inhibitor, added to repair mortars, and as a surface treatment on the reinforcement bars [4]. Adding corrosion inhibitors to the concrete is known to extend the life of the reinforced concrete structures since the time to initiation of corrosion on the rebar is extended due to the addition of these inhibitors. However, adding a corrosion inhibitor directly to concrete may reduce the effectivity of corrosion inhibitor since some parts of corrosion inhibitor can get leached out before they are consumed. Another issue is that some corrosion inhibitors can adversely react with the concrete, leading to reduced mechanical properties of concrete. calcium nitrate $(\mathrm{CN})$ was chosen for this study due to its corrosion inhibiting properties for steel. To release calcium nitrate from the microcapsules the microcapsule must be ruptured from a crack forming in the concrete matrix. This will initiate the corrosion inhibition process, as calcium nitrate will act as an anodic inhibitor against chloride-induced corrosion [5].

Goldsberry et al. [6] evaluated the effect of calcium nitrates in reinforced concrete. They indicated that the addition of microcapsules may increase the chloride penetration and sufficient inhibitor condition is required to mitigate the corrosion process.

This paper aims to evaluate the effect of the corrosion inhibitors on rebar using the pre-cracked samples which simulate the crack occurred by the other stresses rather than corrosion, such as heavy loads on building or bridge applications. In this research, we present the effect of the corrosion inhibitor, calcium nitrate, with different concentration which were exposed to the corrosive environment continuously.

\footnotetext{
* Corresponding author: hcastaneda@tamu.edu
} 


\section{Experimental procedure}

\subsection{Encapsulation of calcium nitrate}

The microencapsulation procedure was adapted from a previous study [7]. The process is based on a water-in-oil suspension polymerization reaction of polyureaformaldehyde, where a $25 \%$ calcium nitrate solution (by weight) was encapsulated as the core material. The suspension polymerization reaction was enabled by heating at higher than room temperature $\left(40{ }^{\circ} \mathrm{C}\right)$ in the presence of an acid catalyst (sulfonic acid) for 2 hours. The sulfonic acid concentration used was of $0.25 \%$ by wt. of organic solvent. Once the microcapsules were synthesized, any trace of sulfonic acid on the microcapsules' surface was neutralized by washing the microcapsule slurry with a $1 \%$ sodium bicarbonate solution. The microcapsules were then recovered through a vacuum filtration.

\subsection{Concrete mix design}

A water-cement ratio of 0.48 was selected through preliminary laboratory tests. The nominal maximum aggregate size was $19 \mathrm{~mm}$ for the coarse aggregate, and $4.76 \mathrm{~mm}$ for the fine aggregate, respectively. The microcapsules were embedded at varying concentrations of microencapsulated corrosion inhibitors by weight of cement to determine the minimal dosage required to mitigate corrosion considerably. A superplasticizer was added to increase the workability of the concrete mix. A defoaming agent was also added at a dosage of $0.10 \%$ by weight of cement to counter the increases in air voids caused by the addition of microcapsules in concrete. The details of the concrete mix design are shown in Table 1.

Table 2 shows the characteristics of the specimens used in this study, where two $75 \mathrm{~mm} \times 150 \mathrm{~mm}$ cylinders were poured per specimen group. Given that the microcapsules need to be ruptured during cracking to release the calcium nitrate, it was important to damage the concrete specimens in a controlled manner. As such, polymer fibers were added to increase the ductility of concrete, so as to prevent sudden failure when cracking the specimens. After 14 days of curing in a $95 \%$ relative humidity chamber, the specimens were subjected to a splitting tensile test, where a displacement rate $(0.005$ in/min) was applied until a crack was induced. The crack size was around $0.3 \mathrm{~mm}$.

Table 1. Concrete mix design.

\begin{tabular}{|c|c|}
\hline Material Description & $\begin{array}{c}\text { Proportions } \\
\left(\mathrm{kg} / \mathrm{m}^{3}\right)\end{array}$ \\
\hline Aggregate 1: Sand, Southern Aggregates, LA & 744 \\
\hline Aggregate 2: \#67 Limestone, Pine Bluff & 1151 \\
\hline Cement: Holcim Type I & 297 \\
\hline Water: Mixing water & 142 \\
\hline Air $(\%)$ & 5.0 \\
\hline $50 \mathrm{~mm}$ Polymer Fibers** & 1.8 \\
\hline Admixture 1: Adva $195(\mathrm{ml} / 100 \mathrm{~kg})$ & 195 \\
\hline Admixture 2: Microcapsules* (\%) & $\begin{array}{l}0.00 \%, 0.50 \%, \\
2.00 \%, 5.00 \%\end{array}$ \\
\hline $\begin{array}{c}\text { Admixture 3: TEGO Antifoam MR 1015* } \\
(\%)\end{array}$ & 0.10 \\
\hline
\end{tabular}

\subsection{Exposure of concrete samples}

The cylindrical concrete beams were pre-cracked before the exposure to release the calcium nitrate from the microcapsules. For the corrosive environment a $5.00 \%$ by weight $\mathrm{NaCl}$ brine was used to simulate an aggressive marine environment. Before exposure the top and bottom of the cylindrical samples were sealed with an epoxy to limit the exposure area of the rebar to that in the middle of the sample. To determine the effectiveness of the corrosion inhibitors, the electrochemical tests were performed as follow.

\subsection{Electrochemical testing}

During exposure of the concrete samples, electrochemical tests were performed for 10 days. The electrochemical tests performed were open circuit potential (OCP) and electrochemical impedance spectroscopy (EIS). All tests were performed with a three-electrode system with saturated calomel electrode as the reference electrode, and a graphite rod as the counter electrode (Figure 1). The EIS testing was carried out from $10 \mathrm{kHz}$ to $0.01 \mathrm{~Hz}$ with an amplitude of $10 \mathrm{mV}$.

Table 2. Samples tested in this study.

\begin{tabular}{|c|c|c|c|c|c|c|}
\hline SampleID & $\begin{array}{c}\text { Corrosion } \\
\text { Inhibitor }\end{array}$ & $\begin{array}{c}\text { Mechanism of } \\
\text { Protection }\end{array}$ & $\begin{array}{c}\text { Microcapsule } \\
\text { Concentration (\% } \\
\text { by wt. of cement) }\end{array}$ & $\begin{array}{c}\text { Corrosion Inhibitor } \\
\text { Concentration (\% by } \\
\text { wt. of cement) }\end{array}$ & $\begin{array}{c}\text { Fiber } \\
\text { Reinforced? }\end{array}$ & Pre-Cracked? \\
\hline CTRL & Control & N/A & $0.00 \%$ & $0.00 \%$ & Y & Y \\
\hline CN C 0.50 & Calcium Nitrate & Microcapsule & $0.50 \%$ & $0.11 \%$ & Y & Y \\
\hline CN C 2.00 & Calcium Nitrate & Microcapsule & $2.00 \%$ & $0.44 \%$ & Y & Y \\
\hline CN C 5.00 & Calcium Nitrate & Microcapsule & $5.00 \%$ & $1.10 \%$ & Y & Y \\
\hline
\end{tabular}




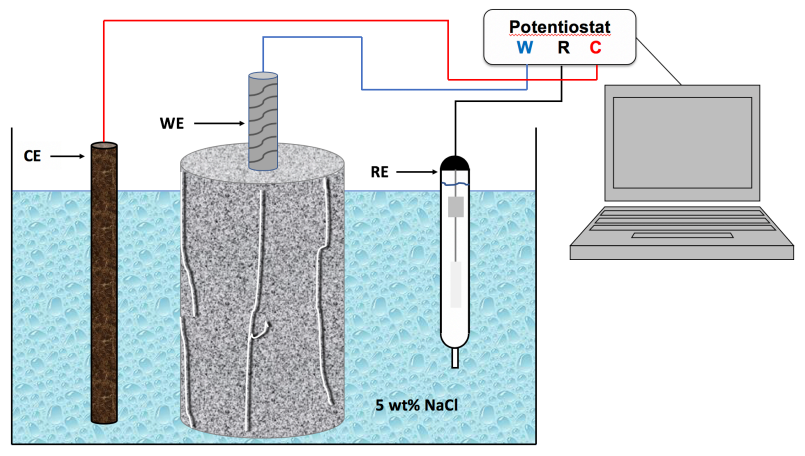

Fig. 1. Experimental set-up for open circuit and electrochemical impedance spectroscopy measurement.

\section{Results and Discussion}

Figure 2 shows an evolution of OCP values during 10 days of testing. In general, the control sample (without the microcapsule) showed the most active corrosion process compared to the microcapsule samples, as indicated by its lowest OCP values. It is also observed that the sample with $0.50 \mathrm{wt} . \%$ of microcapsules $(\mathrm{CN} \mathrm{C}$ $0.5 \%$ ) followed the similar trend found in the control sample, but the OCP value of $\mathrm{CN} \mathrm{C} 0.5 \%$ decreased more gradually at more positive values. This may indicate there was a release of corrosion inhibitor from the capsule due to crack but the concentration was not sufficient to passivate the rebar surface under the crack.

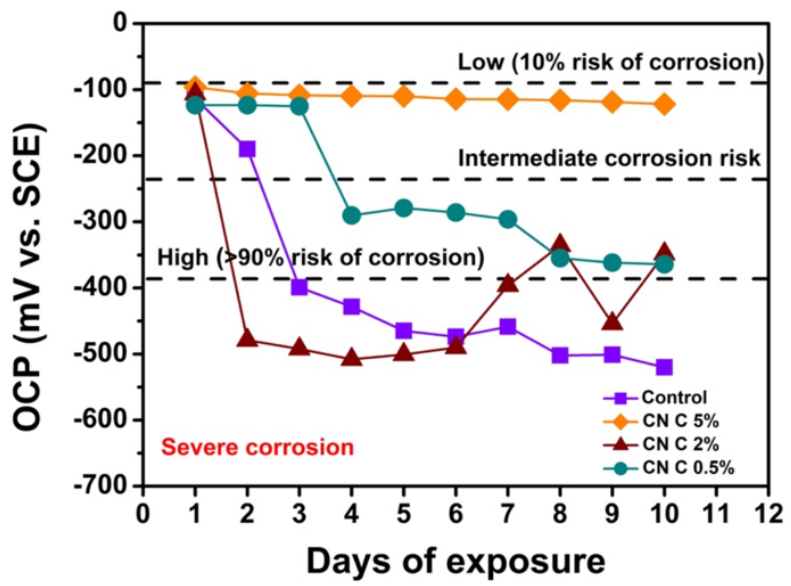

Fig. 2. OCP change over the experimental period.

The sample with 2.00 wt.\% of microcapsules (CN C $2 \%$ ) showed the OCP trend that reflects the effect of inhibitor. The OCP values decreased during the first 4 days, but they then tend to be increased to be more positive as the inhibitor was released and activated. The last OCP value of this sample which was $-350 \mathrm{mV}$ vs. SCE indicated that corrosion inhibitor could not give adequate corrosion protection regardless a passivation effect that can be seen from day 6 to 10 . After 10 days, the OCP values for $\mathrm{CN} \mathrm{C} 0.5 \%$ and $\mathrm{CN} \mathrm{C} 2 \%$ were almost the same and were located in the high corrosion zone ( $>90 \%$ risk of corrosion). The sample with 5.00 wt.\% microcapsule (CN C 5\%) showed a better inhibiting performance compared to any other samples as its OCP values were far more positive than control and other inhibited samples. This suggests an addition of
$5.00 \mathrm{wt} . \%$ microcapsule into the concrete is adequate to provide a corrosion protection to rebar.

Figures 3-5 show the comparison of the EIS results between the control sample and 2.00 wt.\% microcapsule sample. Nyquist plots for the control (Figure 3a) and CN C 2\% (Figure $3 \mathrm{~b}$ ) present the similar magnitude of real part of impedance (X-axis) but the imaginary part showed that the impedance for $\mathrm{CN} \mathrm{C} 2 \%$ is higher. The semicircle Nyquist plot is observed more clearly in the Nyquist plot of CN C $2 \%$ from day 2 - 9. The final impedance found in $\mathrm{CN} \mathrm{C} 2 \%$ sample was found to be higher than the one for the control sample, indicating better corrosion resistance in CN C 2\% sample. The EIS spectra for CN C 5\% sample was found to be the best as indicated by its highest modulus of impedance and phase angle (not shown in this manuscript), indicating a perfect inhibiting effect. However, we found that $\mathrm{CN} \mathrm{C} 2 \%$ sample had more interesting findings to be shown in this manuscript regarding how microencapsulated $\mathrm{CN}$ corrosion inhibitor worked. The CN C $2 \%$ sample clearly showed a transition of passive - active repassivation while $\mathrm{CN} \mathrm{C} \mathrm{5 \%} \mathrm{sample} \mathrm{only} \mathrm{showed} \mathrm{a}$ constant passivation behavior.
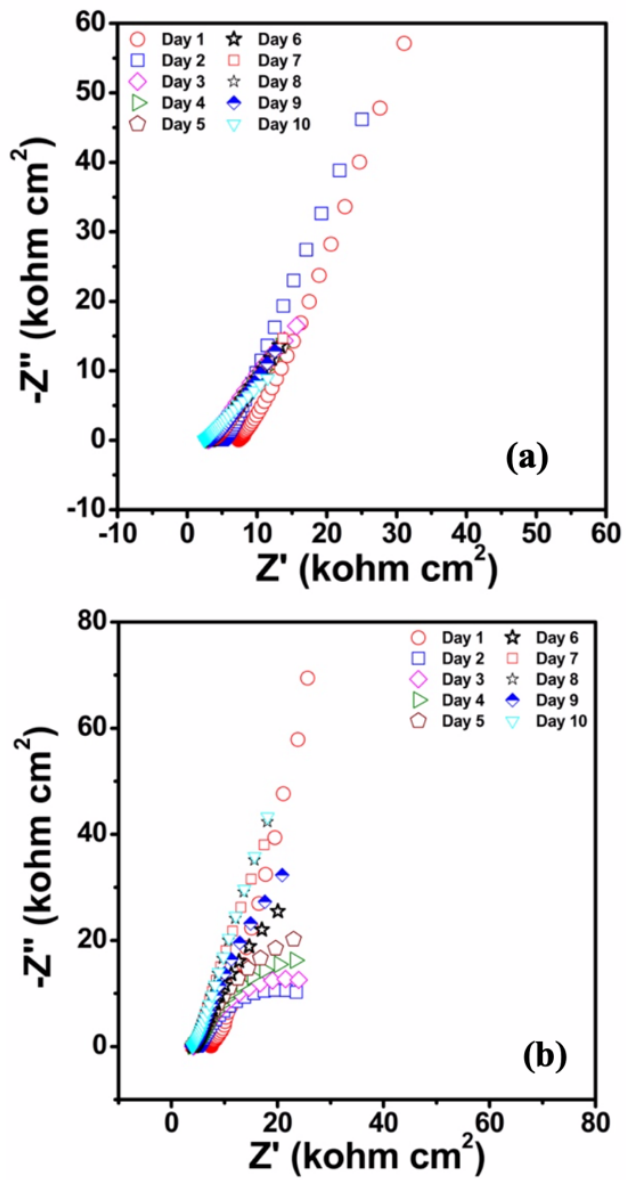

Fig. 3. Nyquist plots for (a) Control and (b) CN C 2\%.

From the Bode plots shown in Figure 4, the modulus of impedance for the control sample (Figure 4a) was lower than the one for the sample with CN C 2\% (Figure $4 \mathrm{~b}$ ), indicating a lower corrosion resistance for the control sample. The modulus of impedance was found to be decreased from 65 to $15 \mathrm{kohm} \cdot \mathrm{cm}^{2}$ for the control 
sample, whereas it was 100 to $50 \mathrm{kohm} \cdot \mathrm{cm}^{2}$ for $\mathrm{CN} \mathrm{C}$ $2 \%$. The Phase angle plots for the control sample and $\mathrm{CN} \mathrm{C} 2 \%$ are presented in Figure 5. Unlike the control sample (Figure 5a) that showed a continuous corrosion activation, CN C 2\% sample (Figure 5b) showed a passive-active-repassivation transition behavior during 10 days of testing. This transition is clearly shown by a change in the number in time constant at the lowest frequency in $\mathrm{CN} \mathrm{C} 2 \%$ sample. At day 1, there was only one time constant, indicating the rebar was still passive. However, at day 2 , the phase angle dropped from 70 to $20^{\circ}$ which indicated a change from semi capacitive to resistive behavior. This decrease in phase angle was accompanied by the presence of second time constant at the low frequencies which corresponded to active corrosion process. From day $3-9$, the phase angle increased from 30 to $60^{\circ}$ and the second time constant gradually disappeared. At day 10, the second time constant almost disappeared and the phase angle reached almost $70^{\circ}$, which was the same as the phase angle at day 1 . The disappearance of the second time constant is attributed to the repassivation of rebar by corrosion inhibitor.
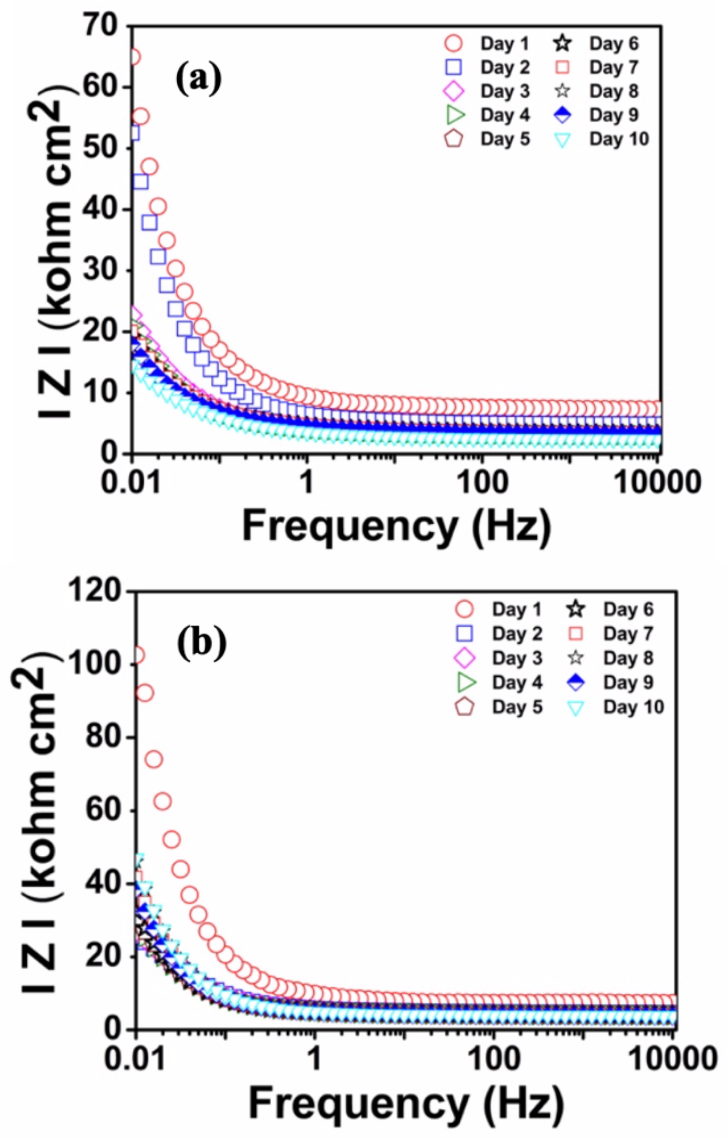

Fig. 4. Bode plots for (a) Control and (b) CN C $2 \%$.
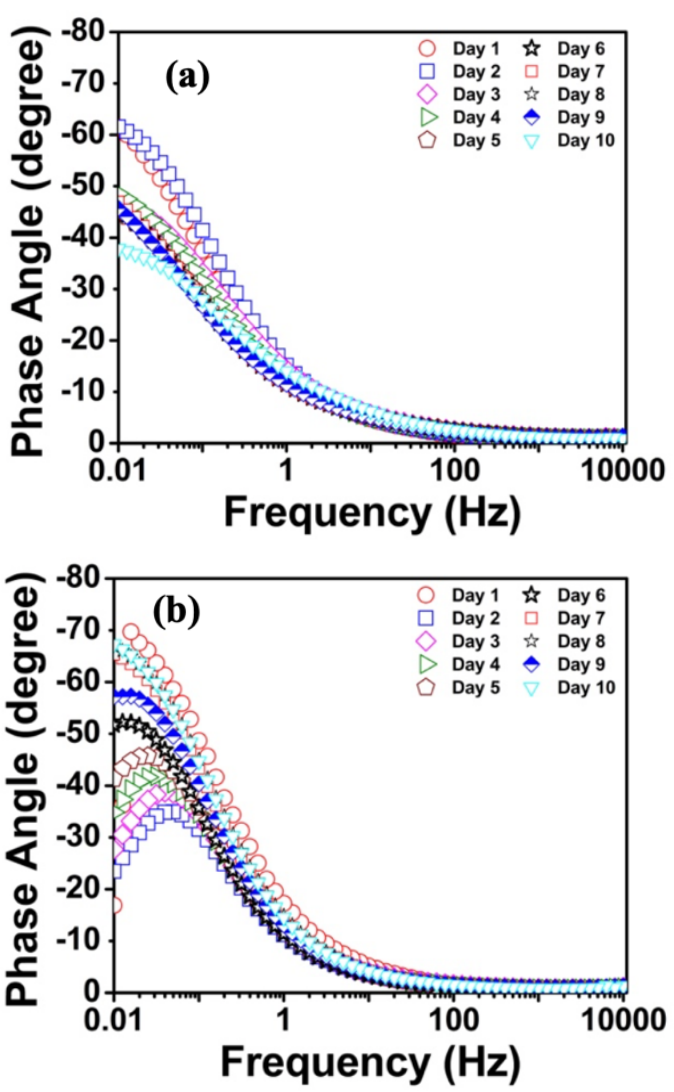

Fig. 5. Phase angle plots for (a) Control and (b) CN C 2\%.

\section{Conclusions}

The effect of encapsulated corrosion inhibitors in the concrete matrix was experimentally explored in this study. From both OCP values and EIS spectra, it was found that an addition of calcium nitrate corrosion inhibitor-containing microcapsules into cracked concrete beams successfully repassivated or maintained the passivity of the rebar when the concrete was cracked. This corrosion inhibitor repassivated the rebar by forming a passive layer on the rebar surface under the crack. This repassivation process was evident by an increase of OCP values to more positive values or by stable OCP values at around $-100 \mathrm{mV}$ vs SCE during corrosion testing. An increase in phase angle after corrosion activation for the sample containing $2.00 \mathrm{wt} . \%$ microcapsule clearly showed this repassivation process due to corrosion inhibitor. These results suggest that calcium nitrate encapsulated in polyurea-formaldehyde is a good candidate for anticorrosion system in the concrete. The optimum concentration of microcapsule containing calcium nitrate for maintaining the passivity on rebar in the cracked concrete was found to be $5 \mathrm{wt} . \%$.

\section{References}

1. Tuutti, K. (1982). Corrosion of steel in concrete. In, 469. S-100 44 Stockholm: Swedish Cement and Concrete Research Institute. 
2. Broomfied, J.P. (2007). Corrosion of Steel in Concrete: Understanding, investigation, and repair (Taylor \& Francis: London and New York).

3. Grubb, J.A., Limaye, H.S., and Kakade, A.M. (2007). Testing $\mathrm{pH}$ of Concrete: Need for a Standard Procedure. In Concrete International, 7883. American Concrete Institute (ACI).

4. Elsener, B. (2001). Corrosion inhibitors for steel in concrete: state of the art report (published for the European Federation of Corrosion by Maney on behalf of the Institute of Materials: London).

5. Østnor, T.A., and Justnes, H. (2011). Anodic corrosion inhibitors against chloride induced corrosion of concrete rebars. Advances in Applied Ceramics, 110, 131-36.

6. Goldsberry, R., Milla, J., and McElwee, M. (2018). Evaluation of Microencapsulated Corrosion Inhibitors in Reinforced Concrete. In International Congress on Polymers in Concrete (ICPIC 2018), edited by Taha MMR, 99-105. Springer International Publishing.

7. Milla, J., Hassan, M.M., and Rupnow, T. (2017). Evaluation of Self-Healing Concrete with Microencapsulated Calcium Nitrate. Journal of Materials in Civil Engineering, 29, 04017235. 